\title{
Stress and the menopausal transition in Campeche, Mexico
}

\author{
Lynnette Leidy Sievert ${ }^{*}$ (D), Laura Huicochea-Gómez ${ }^{2}$, Diana Cahuich-Campos ${ }^{2}$, Dana-Lynn Ko'omoa-Lange ${ }^{3}$ \\ and Daniel E. Brown ${ }^{4}$
}

\begin{abstract}
Background: Stress has been implicated as a factor in the presence and severity of symptoms during the menopausal transition. Our primary aim was to test the hypothesis that stress-sensitive biological measures and self-reported stress would be positively associated with a greater likelihood and intensity of hot flashes. Our secondary aim was to examine measures of stress in relation to the most often reported symptoms in Campeche, Mexico. We also hypothesized ethnic differences (Maya versus non-Maya) in relation to measures of stress and symptom reports.

Methods: Participants aged 40-60 ( $n=305)$ were drawn from multiple sites across the city of San Francisco de Campeche to achieve a generally representative sample. Measures included C-reactive protein (CRP), an indicator of inflammation; Epstein-Barr virus antibodies (EBV-Ab), an indicator of immune function; the Perceived Stress Scale (PSS); a symptom checklist; anthropometric measures; and a questionnaire that elicited symptoms, ethnicity (based on language, birthplace, and last names of the woman, her parents, and her grandparents) and ten dimensions of socioeconomic status (SES). The relationships between symptoms and stress-sensitive biological and self-reported measures were examined in bivariate analyses, and with logistic and linear regressions.
\end{abstract}

Results: The twelve most common symptoms reported, in descending order of frequency, were tiredness, muscle and joint pain, nervous tension, problems concentrating, feeling depressed, difficulty sleeping, headaches, feeling of ants crawling on the skin, loss of interest in sex, urinary stress incontinence, hot flashes, and night sweats. PSS scores were significantly associated with the likelihood of seven symptoms (yes/no), and with the intensity of ten symptoms after controlling for ethnicity, SES, education, cohabitation status, parity, smoking, body mass index, and menopausal status. The stress-sensitive biological measures of immune function (EBV-Ab and CRP) were not significantly associated with midlife symptoms. The PSS was associated with more symptoms among the Maya (e.g., feeling nervous/tense and having difficulty concentrating) than non-Maya.

Conclusion: PSS scores were associated with the intensity, but not the likelihood, of hot flashes. Other symptoms were also associated with self-reported stress but not with physiological measures. Maya/non-Maya differences may indicate that either symptoms or stress were experienced and/or reported in culture-specific ways.

Keywords: Menopause, Stress, Hot flashes, Night sweats, Fatigue, Sleep difficulties, Depression

\footnotetext{
* Correspondence: leidy@anthro.umass.edu

'Department of Anthropology, Machmer Hall, 240 Hicks Way, UMass

Amherst, Amherst, MA 01003-9278, USA

Full list of author information is available at the end of the article
} 


\section{Background}

The menopausal transition is often characterized by hot flashes and night sweats [1], fatigue and body aches [2], difficulty sleeping [3], and transient depression [4]. Some symptoms can be attributed to the changing hormone levels associated with the loss of ovarian follicles, including fluctuating estradiol and increases in follicle stimulating hormones [5, 6]. However, some symptoms may be better explained by combining physiological information with the social changes that coincide with this time of life. For example, a woman's children are likely to be adolescents with their own challenges, husbands may be undergoing transition in social status such as retirement or struggling with health issues, and parents may be in need of substantial levels of care $[7,8]$.

During the menopausal transition, stress may be a contributor to trouble sleeping, depression [9, 10], and/ or symptoms that may have a psychosomatic component [11]. For example, in cross-cultural work among women aged 45-55, Sievert et al. [12] found that job change was associated with an increased likelihood of nervous tension, difficulty concentrating, headaches, and fatigue in the U.S., but not in Spain. In Spain, but not the U.S., household change was associated with depressed mood and difficulty concentrating. These differences show that stress is variable and context dependent. It appears that job change may be experienced as more stressful in the U.S., whereas household change may be more stressful in Spain.

Specific to hot flashes, stress has been identified as a determinant in some [13-17], but not all [12, 18, 19] studies of factors associated with hot flashes. In a laboratory setting, where symptomatic women were exposed to a variety of stressors, there were $57 \%$ more self-reported hot flashes during stress periods compared to non-stress periods [20]. In the Study of Women's Health Across the Nation (SWAN), after adjusting for ethnicity, lifestyle, and other confounding variables, self-reported perceived stress was significantly associated with self-reported vasomotor symptoms (adjusted odds ratio 1.4, 95\% confidence interval 1.2-1.6) [15], and significantly related to a longer persistence of self-reported hot flashes into the postmenopausal period [13]. In a 13-year longitudinal study in Philadelphia, women who reported moderate or severe hot flashes during the study period had a higher baseline Perceived Stress Scale (PSS) score (21.9) compared to women with mild hot flashes (19.5) or no hot flashes $(18.2, p<0.01)$. Stress was not significantly associated with the duration of self-reported hot flushes in a multivariable model [14].

Cortisol is a stress-sensitive biological measure [21] that has been examined in relation to hot flashes. Two early laboratory studies showed an increase in cortisol levels during and after monitored hot flashes [22, 23]. In the
Seattle Women's Health Study, women with increased urinary cortisol had significantly greater self-reported hot flash and cold sweat symptom severity compared to women without increased cortisol [24]. In Modena, Italy, women with self-reported severe hot flashes had significantly higher levels of 24-h urinary cortisol compared to women with none to moderate vasomotor symptoms [25]. Hot flash report has also been associated with higher salivary cortisol levels in the early afternoon [26]. In a small study where women with hot flashes were measured by an ambulatory monitor, objectively measured hot flashes were associated with significantly higher salivary cortisol levels at 15, 30, and 45 min post-waking compared to women without biometrically measured hot flashes [27].

Not all studies have shown a consistently positive relationship between hot flashes and cortisol levels. For example, hot flash report has not been associated with the cortisol awakening response or diurnal variation in cortisol levels $[26,28,29]$. One study found greater self-reported hot flash severity associated with a flatter diurnal slope in salivary cortisol [30].

Self-reported hot flashes and other symptoms have been shown to vary across ethnicity within the same country [31-33]. Self-reported stress has also been shown to vary with ethnicity. For example, Brown [34, 35] compared levels of stress across two Filipino-American ethnic groups to show that individuals from Visayan backgrounds self-reported significantly higher levels of stress compared to individuals of Ilocano descent. At the same time, there was no difference in the 24-h excretion rates of norepinephrine and epinephrine between the two groups. Brown also found that Filipino American women (mostly Ilocanos) were significantly more likely to record being anxious in a diary compared to European American women, but European Americans had higher elevations in ambulatory blood pressure when they did report anxiety [36]. Ethnic differences were also found in response to doing household chores: Filipino American women were more likely to report being anxious during chores than European Americans, but the European American women had higher diastolic BP while doing chores than the Filipino Americans [36]. Ethnic differences in the report of stress may reflect psychosocial differences [37], or culturally-based reporting biases [38]. For these reasons, the study reported here examined self-reported stress and symptom frequencies between Maya and non-Maya women.

Previous studies of menopause among Maya women in the Yucatán Peninsula of Mexico found an early mean recalled age at natural menopause of 44 years, compared to 52.5 years in the U.S. [39-41]. An in-depth ethnographic study documented an absence of self-reported hot flashes among rural Maya women [42]. According to 
Beyene, Maya women explained menopause as something that occurred when a woman used up her menstrual blood ([43], page 119). These women perceived menopause to be "a life stage free of taboos and restrictions, offering increased freedom of movement" (p.120). Other investigators recorded higher levels of hot flash frequencies among urban (49\%) and rural (41\%) Maya women in the Yucatán peninsula [44].

This study administered the PSS, as used in the SWAN and Philadelphia studies, to measure self-reported stress. To our knowledge, this will be the first study to examine hot flashes and other symptoms at midlife in relation to Epstein-Barr virus antibodies (EBV-Ab) [45, 46]. Both $\mathrm{C}$-reactive protein (CRP) and EBV-Ab have been positively associated with high stress levels $[47,48]$. CRP is an acute-phase protein that is commonly used as a measure of general inflammation. Because chronic stress is associated with elevated inflammation levels [49], this protein has been used as a marker of both acute and chronic stress $[50,51]$. With regard to EBV-Ab, most people are chronically infected with EBV. When an individual is stressed, down-regulation of the immune system allows the virus to replicate, and antibodies to the virus increase in the blood stream. Accordingly, an elevated EBV-Ab level has been used as a biological marker of stress [47, 52].

The primary aim of this study was to test the hypothesis that two biological measures potentially sensitive to stress and a self-reported measure of stress would be associated with a higher likelihood and intensity of hot flashes after controlling for potential confounders. Our secondary aim was to examine the stress-sensitive measures and self-reported stress in relation to the most commonly reported symptoms in Campeche, Mexico. Based on the results of other cross-cultural studies [12, 36] detailed above, we paid particular attention to ethnic differences in nervous tension, difficulties concentrating, headaches, fatigue, and depressed mood, as well as hot flashes and trouble sleeping. We hypothesized that all stress measures would be associated with the frequency and intensity of each of the 12 most-reported symptoms in bivariate analyses, and after controlling for potential confounders. We also hypothesized ethnic differences (Maya vs. non-Maya) in relation to measures of stress and symptom reports [38]. Other variables that could affect both stress measures and symptoms were collected, including age, menopausal status, level of education, socioeconomic status (SES), body mass index (BMI), ethnicity, marital status and cohabitation with husband or partner, parity, and smoking habits.

\section{Methods}

\section{Sample}

The study took place in San Francisco de Campeche, a city of approximately 250,000 people [53] located on the western coast of the Yucatan peninsula. Nearly $12 \%$ of the city's population speaks Maya [53]. Women aged 40-60 years were drawn from businesses, schools, the city market, and by presentations given in homes. The use of several recruitment methods assured a diverse, although not random, sample of the city's population. These participants make up the urban component of a larger study of menopause in the state of Campeche [54]. In the city, a total of 305 women participated in interviews and anthropometric measures, with a subsample of 162 participants providing finger stick blood samples. Of those 162 women, 109 provided sufficient blood for the assay of both CRP and EBV-Ab levels.

The study was approved by the Institutional Review Board of the University of Massachusetts Amherst; the Human Subjects Committee of the University of Hawaii at Hilo; and the Committee for Ethics in Research of the Secretary of Health in the State of Campeche, Mexico. All participants signed a letter of consent after lengthy explanation in Spanish.

\section{Measures}

All participants answered questions related to their age, education, parity, and smoking status. An SES index was created from 10 dimensions related to housing construction, household composition, and infrastructure, such as, access to drinking water and type of cooking fuel. Within the city of Campeche, the range in SES index was from 22 to 39. With regard to marital status, $96 \%$ of married women $(n=160)$ and $73 \%$ of women with a partner $(n=26$; union libre $)$ lived with their partner and, therefore, the variable of interest used in the analyses here was whether or not a woman cohabited with a husband or partner.

Maya/non-Maya ethnicity was assessed on the basis of each woman's two last names, whether she could speak or understand Maya, and place of birth. The same information was collected with regard to her parents and grandparents. Women were categorized as Maya, not Maya, or not able to be clearly defined on the basis of this information from all three generations. There were 40 participants for whom an ethnic was unclear because of missing information (e.g., not everyone knew the language spoken by their grandparents).

Menopausal status was defined by STRAW+ 10 stages: (1) regular menstruation, (2) changes in the number of days or quantity of blood, (3) more or less frequent menstruation, (4) a change in periods of more than 6 days, (5) 2 months or more have passed without a period, and (6) more than 12 months have passed without a period [55]. Stages 1 and 2 were categorized as pre-menopausal, stages 3 to 5 as peri-menopausal, and stage 6 as postmenopausal. 
Stature was measured with a Seca 213 stadiometer to the nearest $0.1 \mathrm{~cm}$. Weight was measured to the nearest $0.1 \mathrm{~kg}$ with a digital scale. BMI was computed as $\mathrm{kg} / \mathrm{m}^{2}$.

All participants completed the PSS that has been previously used in Mexican populations [56]. The PSS is a well validated 10 -item questionnaire that directly queries levels of stress experienced in the past month, and the degree to which one's life is unpredictable, uncontrollable, and overloaded [57, 58].

Participants were asked about the presence or absence of 19 symptoms during the past 2 weeks including hot flashes (Ha tenido calores o bochornos?) and night sweats (En la noche ha tenido sudoraciones?). This "everyday symptom list" has been used in many studies [59-61], including in Mexico [62]. Symptom intensities were reported as: $0=$ nada; $1=u n$ poco; $2=$ mucho; and $3=$ muchisimo. Twelve symptoms had a frequency of $45 \%$ or higher in the city of Campeche. The cut off of $45 \%$ was selected in order to include hot flashes and night sweats in the analyses below. The 12 symptom reports were totaled to derive a total number of symptoms reported for each individual. Also, the intensity of the 12 symptoms were totaled to derive a total symptom intensity score for each participant.

Blood was collected by finger stick onto Whatman \#903 Protein Saver filter paper sample cards [47], dried for $4 \mathrm{~h}$, and immediately frozen in the Huicochea laboratory at ECOSUR, Campeche. The cards were carried to the United States by LLS, and mailed overnight to the University of Hawaii at Hilo with ice packs. The cards were then transferred to freezer storage at $-30{ }^{\circ} \mathrm{C}$ until analysis.

To determine the presence of EBV - Viral Capsid Antigen (VCA) in dried blood spot samples, an EBVVCA enzyme-linked immunosorbent assay (Diamedix Corporation, Miami Lakes, FL), was modified for sampling dried blood spots. Briefly, a sample of each blood spot was taken by punching a single $6 \mathrm{~mm}$ disc using a standard hand held hole puncher. The blood spot samples were incubated in elution buffer overnight, on a platform shaker at low speed. $100 \mathrm{uL}$ of the cut-off calibrator, controls and samples were transferred to the antigen wells. The samples and controls were allowed to incubate at room temperature for $30 \mathrm{~min}$. The contents of the wells were discarded, and the wells were washed three times with wash solution. $100 \mathrm{uL}$ of conjugate was pipetted into each well, and allowed to incubate at room temperature for $30 \mathrm{~min}$. The contents were discarded, and the wells were washed three times in wash solution. Next, $100 \mathrm{uL}$ of the substrate was pipetted into each well, and the wells were incubated at room temperature for $30 \mathrm{~min}$. After incubation with substrate, $100 \mathrm{uL}$ of stop solution was pipetted into each well. The absorbance was determined at $450 \mathrm{~nm}$. All controls and samples were assayed in duplicate [45].
To determine the index value for each participant, the following formula was used:

$$
\begin{aligned}
& \text { Absorbance of sample } \\
& \text { Mean absorbance of } \\
& \text { cut-off calibrator }
\end{aligned}
$$

Samples with an index value $\geq 1.10$ were determined to be positive for VCA IgG antibody.

CRP enzyme-linked immunosorbent assay (Abcam, Cambridge, MA) was used to quantitatively measure human CRP in blood spots following the methods of McDade et al. [63]. CRP values in blood spots were converted into the equivalent values of CRP in plasma by the following: $\left(\mathrm{CRP}_{\text {bloodspot }} * 1.15\right)-0.13=\mathrm{CRP}$ Plasma [63]. None of the participants had a $\mathrm{CRP}_{\text {Plasma value }}$ greater than $10.0 \mathrm{mg} / \mathrm{L}$, an indicator of an active infection which would have led to exclusion from analyses involving CRP and EBV-Ab [64].

\section{Analyses}

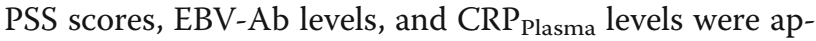
praised for normal distribution. PSS scores were normally distributed and examined in relation to ethnic categories (Maya, not Maya, difficult to categorize) by ANOVA and in relation to each symptom (yes/no) by t-tests. EBV-Ab and $\mathrm{CRP}_{\text {Plasma }}$ levels were not normally distributed, and therefore were examined in relation to ethnic categories and in relation to each symptom by two-tailed Mann Whitney tests. Spearman correlations were examined between EBV-Ab values, CRP Plasma levels, and PSS scores.

Logistic regressions were performed with each of the 12 symptoms (none vs. any level of symptom experience) as a dependent variable in a separate regression model. Analyses were carried out separately for each of the three stress measures - PSS scores, EBV-Ab values, and $\mathrm{CRP}_{\text {Plasma }}$ levels; therefore, there were three analyses carried out for each of the 12 symptoms. BMI, SES, education, ethnicity, cohabiting with a husband or partner, parity, smoking, and menopausal status were covariates. Because of the correlation among the covariates SES and education $(r=.465, p<0.001)$, and in order to achieve the best set of variables associated with each symptom, backward stepwise regression was carried out with a probability for entry set at 0.05 and probability for removal set to 0.10 . Because of the multiple testing, we applied an adjusted $p$-value of $p \leq 0.001$ to determine significance. Logistic regressions were repeated separately for women categorized as Maya and non-Maya.

Linear regressions with backwards elimination were carried out for all participants with intensity of symptom reports (nada, un poco, mucho, muchisimo) as dependent variables and PSS scores, EBV-Ab values, $\mathrm{CRP}_{\text {Plasma }}$ levels, 
BMI, SES, education, ethnicity, cohabiting with a husband or partner, parity, smoking, and menopausal status as covariates. As described above, analyses for each symptom were carried out separately for the three stress variables, and analyses were repeated separately for women categorized as Maya and non-Maya, respectively.

\section{Results}

Table 1 presents some characteristics of the sample by ethnicity. The Maya had a significantly lower SES index than non-Maya, but there were otherwise no significant ethnic differences in the listed characteristics. There were no significant differences in the PSS score between Maya and non-Maya women $(t=1.3$, ns); Maya women had significantly higher EBV-Ab (two-tailed Mann Whitney test, $p<0.05$ ), but there was no significant ethnic difference in $\mathrm{CRP}_{\text {Plasma }}$ levels. There were no significant ethnic differences in the frequency of symptoms, the total number of reported symptoms, or the total symptom intensity scores (two-tailed t-tests, ns). Figure 1 shows the frequency of reported symptoms for the entire sample.
For all women in the sample, there was a significant correlation between EBV-Ab values and CRP Plasma levels (Spearman $\rho=0.57, p<0.001$ ), but PSS scores were not significantly correlated with either EBV-Ab values $\left(\rho=-0.08\right.$, ns) or $\mathrm{CRP}_{\text {Plasma }}$ levels $(\rho=-0.02$, ns). Similar correlation results among stress measures were obtained when the ethnic groups were considered separately.

Table 2 presents results for bivariate analyses of the relation between stress measures and reported symptoms (none vs. any level of symptom experience) for all participants. The table gives means and standard deviations of the PSS scores, and medians of the CRP Plasma and EBV-Ab levels. For nine of the 12 symptoms, women who reported the symptom had a significantly higher PSS score compared to women who did not report the symptom $(p \leq 0.001)$. Women with hot flashes and headaches had higher PSS scores, with $p$-values of 0.004 and 0.006 , respectively - slightly above the conservative Bonferroni correction of $p \leq 0.001$. EBV-Ab and $\mathrm{CRP}_{\text {Plasma }}$ values were not significantly higher among women reporting any symptom.

The total number of reported symptoms for each individual was significantly correlated with the PSS score

Table 1 Participant information. Means \pm standard deviations, numbers of participants, or percentages shown

\begin{tabular}{|c|c|c|c|c|}
\hline & Maya & Non-Maya & Could not classify & All \\
\hline $\mathrm{N}$ & 144 & 121 & 40 & 305 \\
\hline $\begin{array}{l}\text { Age at interview } \\
\text { Mean } \pm \text { s.d. }\end{array}$ & $47.9 \pm 5.0$ & $46.9 \pm 5.0$ & $47.5 \pm 5.0$ & $47.5 \pm 5.0$ \\
\hline $\begin{array}{l}\mathrm{BMI}\left(\mathrm{kg} / \mathrm{m}^{2}\right) \\
\text { Mean } \pm \text { s.d. }\end{array}$ & $31.3 \pm 5.2$ & $30.3 \pm 5.8$ & $29.1 \pm 5.3$ & $30.6 \pm 5.5$ \\
\hline $\begin{array}{l}\text { SES Index } \\
\text { Range } 22-39 . \text { Mean } \pm \text { s.d. }\end{array}$ & $32.8 \pm 2.4$ & $33.4 \pm 2.3$ & $33.4 \pm 2.4$ & $33.1 \pm 2.4$ \\
\hline $\begin{array}{l}\text { Education (yrs) } \\
\text { Mean } \pm \text { s.d. }\end{array}$ & $12.8 \pm 4.4$ & $13.8 \pm 4.0$ & $13.3 \pm 4.4$ & $13.2 \pm 4.2$ \\
\hline \multicolumn{5}{|l|}{ Menopause status (\%) } \\
\hline Pre-menopausal & 40.3 & 47.9 & 42.5 & 43.6 \\
\hline Perimenopausal & 20.8 & 24.0 & 22.5 & 22.3 \\
\hline Post - menopausal & 38.9 & 28.1 & 35.0 & 34.1 \\
\hline$\%$ cohabiting with husband or partner & 59.0 & 57.0 & 70.0 & 59.7 \\
\hline $\begin{array}{l}\text { Parity } \\
\text { Mean } \pm \text { s.d. }\end{array}$ & $2.0 \pm 1.1$ & $2.1 \pm 1.2$ & $2.0 \pm 1.4$ & $2.0 \pm 1.2$ \\
\hline Smoking (\%) & 10.4 & 14.9 & 12.5 & 12.5 \\
\hline $\begin{array}{l}\text { PSS score } \\
\text { Mean } \pm \text { s.d. } n=305\end{array}$ & $1.55 \pm 1.6$ & $1.04 \pm 0.6$ & $1.58 \pm 1.7$ & $1.35 \pm 1.3$ \\
\hline $\begin{array}{l}\text { EBV-Ab level* } \\
\text { Mean } \pm \text { s.d. } n=162\end{array}$ & $4.59 \pm 1.4$ & $4.06 \pm 1.7$ & $3.83 \pm 1.6$ & $4.30 \pm 1.6$ \\
\hline $\begin{array}{l}\mathrm{CRP}_{\text {plasma }} \text { level } \\
\text { Mean } \pm \text { s.d. } n=157\end{array}$ & $16.78 \pm 5.2$ & $17.65 \pm 5.9$ & $17.95 \pm 4.5$ & $17.28 \pm 5.4$ \\
\hline $\begin{array}{l}\text { Total symptom score } \\
\text { (range } 0-12 \text {, based on } 12 \text { most common symptoms) }\end{array}$ & $7.4 \pm 3.0$ & $7.4 \pm 2.7$ & $6.9 \pm 3.1$ & $7.3 \pm 2.9$ \\
\hline $\begin{array}{l}\text { Total symptom intensity score (range } 0-33 \text {, based on } \\
12 \text { most common symptoms) }\end{array}$ & $10.9 \pm 6.4$ & $10.4 \pm 6.0$ & $9.3 \pm 5.5$ & $10.5 \pm 6.0$ \\
\hline
\end{tabular}

${ }^{a}$ Ethnic difference, Maya versus non-Maya, $p<0.05$ 


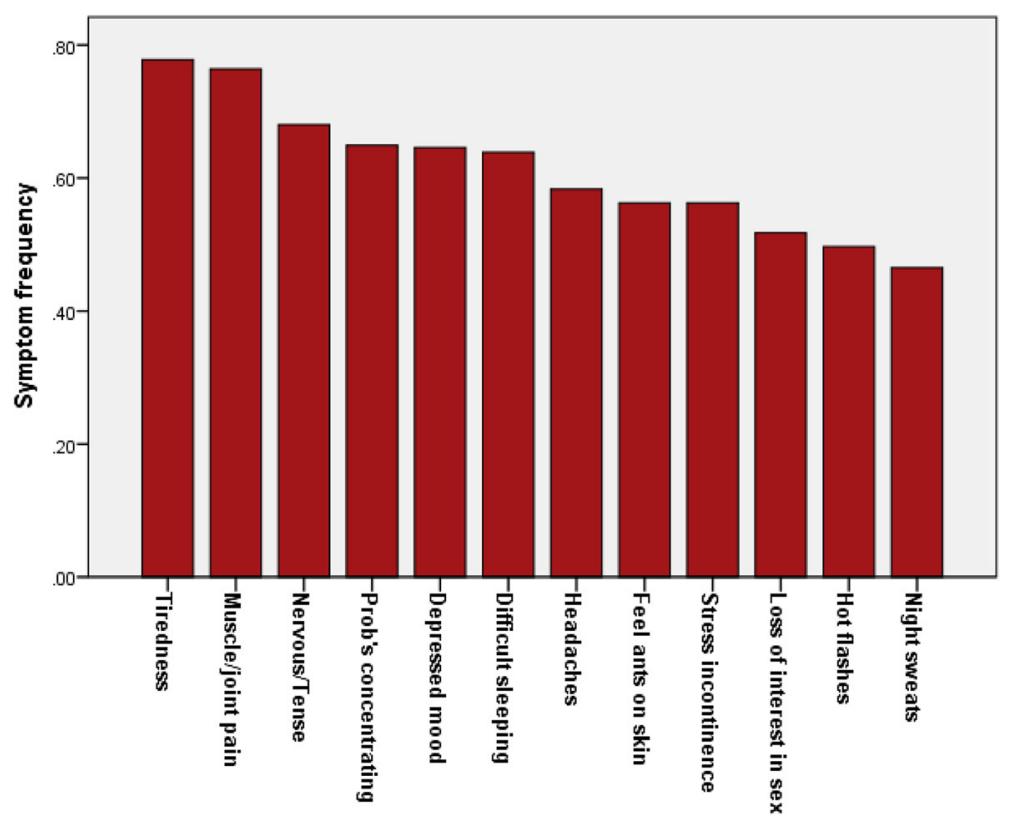

Fig. 1 Frequency of the 12 most often reported symptoms among Maya and non-Maya women living in the city of Campeche, Mexico ( $n=305)$

(two-tailed Spearman correlations, $\rho=0.42, p<0.001$ ), but not with $\mathrm{CRP}_{\text {Plasma }}(\rho=-0.02$, ns) nor EBV-Ab $(\rho=-0.08$, ns) levels. The total symptom intensity score was significantly correlated with the PSS score $(\rho=0.46, p<0.001)$ and EBV-Ab values $(\rho=0.17, p<0.05)$.

Table 3 presents the covariates that remained in the models following backwards stepwise logistic regression for each symptom among all participants. PSS score was significantly, positively associated with the report of tiredness, muscle/joint pain, feeling nervous/tense, problems concentrating, depressed mood, difficulty sleeping, and loss of interest in sex after controlling for BMI, SES, education, ethnicity, cohabiting with a husband or partner, parity, smoking, and menopausal status. Odds Ratios for PSS ranged from 1.10 (95\% CI 1.04-1.15) for loss of interest in sex to 1.22 (95\% CI 1.13-1.32) tiredness. Hot flashes, night sweats, and the feeling of ants crawling on the skin had $p$-values of $0.007,0.004$,

Table 2 Bivariate comparisons of stress levels by symptom complaints. Means \pm standard deviations for PSS scores or medians for CRP Plasma and EBV-Ab levels shown

\begin{tabular}{|c|c|c|c|c|c|c|}
\hline \multirow[t]{2}{*}{ Symptom } & \multicolumn{2}{|c|}{ PSS score by symptom } & \multicolumn{2}{|c|}{ EBV-Ab value by symptom } & \multicolumn{2}{|c|}{ CRPPlasma level by symptom } \\
\hline & No & Yes & No & Yes & No & Yes \\
\hline Tiredness or lack of energy & $13.9 \pm 4.2$ & $18.2 \pm 5.3^{* * *}$ & 0.81 & $1.00^{*}$ & 5.28 & 5.69 \\
\hline Muscle and joint pain & $15.1 \pm 4.6$ & $17.9 \pm 5.5^{* * *}$ & 1.00 & 0.96 & 5.61 & 5.64 \\
\hline Nervous or tense & $15.3 \pm 4.5$ & $18.2 \pm 5.5^{* * *}$ & 0.93 & 1.00 & 5.28 & 5.68 \\
\hline Problems concentrating & $15.4 \pm 4.5$ & $18.3 \pm 5.6^{* * *}$ & 0.94 & 0.99 & 5.57 & 5.65 \\
\hline Depressed mood or sadness & $15.3 \pm 4.3$ & $18.4 \pm 5.6^{* * *}$ & 0.93 & 1.00 & 4.86 & $5.72^{*}$ \\
\hline Difficulty sleeping & $15.1 \pm 5.0$ & $18.6 \pm 5.2^{* * *}$ & 0.86 & 1.01 & 5.34 & 5.68 \\
\hline Headaches & $16.3 \pm 4.7$ & $18.0 \pm 5.8^{* *}$ & 0.94 & 1.00 & 5.48 & 5.69 \\
\hline Feeling of ants crawling on skin & $16.0 \pm 4.7$ & $18.3 \pm 5.7^{* * *}$ & 0.82 & $0.94^{*}$ & 5.33 & 5.48 \\
\hline $\begin{array}{l}\text { Urinary stress incontinence with effort } \\
\text { or laughter }\end{array}$ & $16.4 \pm 4.9$ & $17.9 \pm 5.7^{*}$ & 0.93 & 0.98 & 5.34 & 5.68 \\
\hline Loss of interest in sexual relations & $16.3 \pm 5.2$ & $18.4 \pm 5.4^{* * *}$ & 1.00 & 0.96 & 5.65 & 5.65 \\
\hline Hot flashes & $16.4 \pm 5.2$ & $18.2 \pm 5.4^{* *}$ & 0.94 & 0.98 & 5.59 & 5.67 \\
\hline Night sweats & $16.4 \pm 5.0$ & $18.5 \pm 5.7^{* * *}$ & 0.84 & 1.02 & 5.34 & 5.68 \\
\hline
\end{tabular}

Two tailed t-tests or Mann-Whitney tests, ${ }^{*} p<0.05 ;{ }^{* *} p<0.01 ;{ }^{* * *} p \leq 0.001$ 
Sievert et al. Women's Midlife Health (2018) 4:9

Page 7 of 15

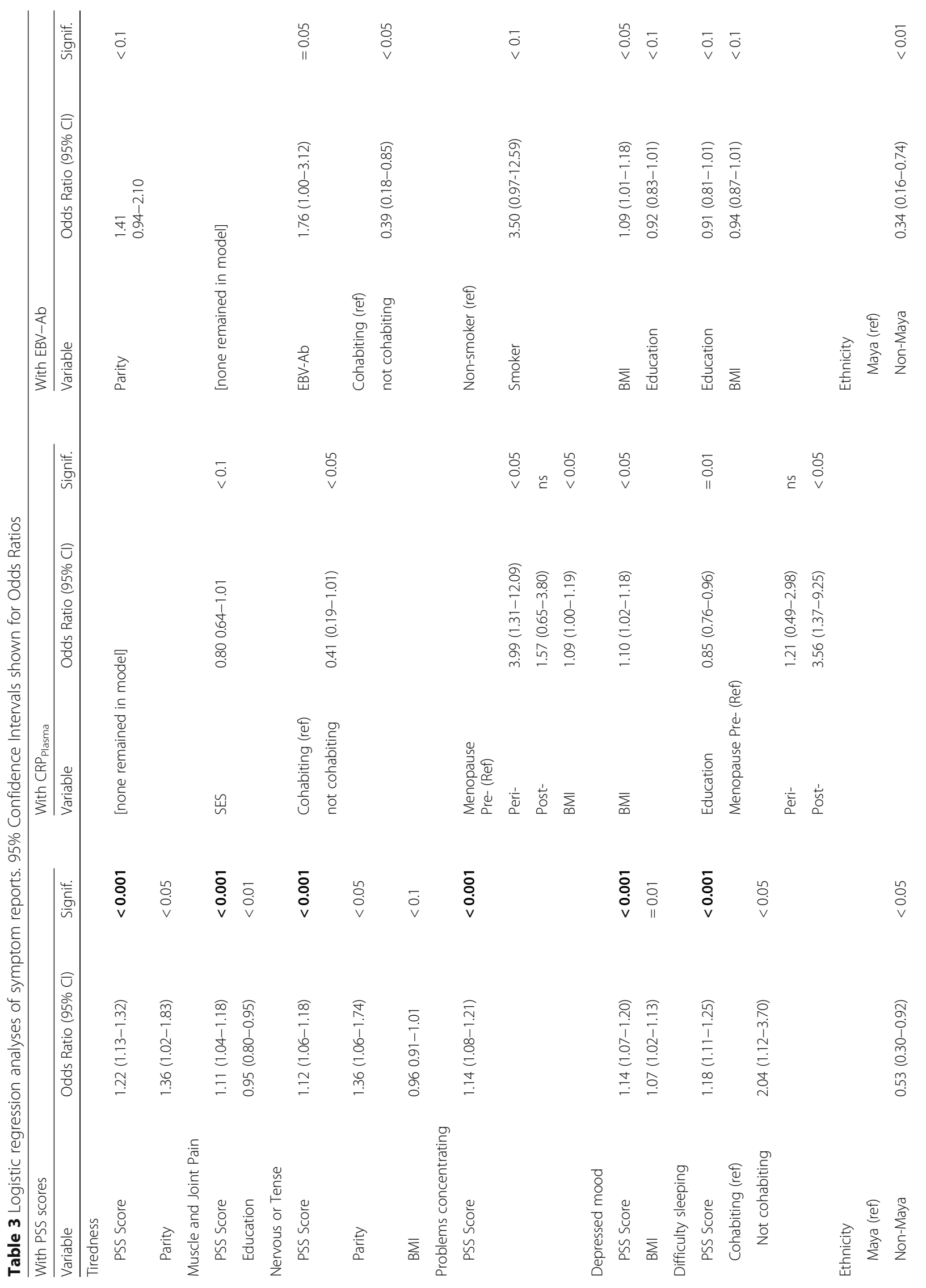


Sievert et al. Women's Midlife Health (2018) 4:9

Page 8 of 15

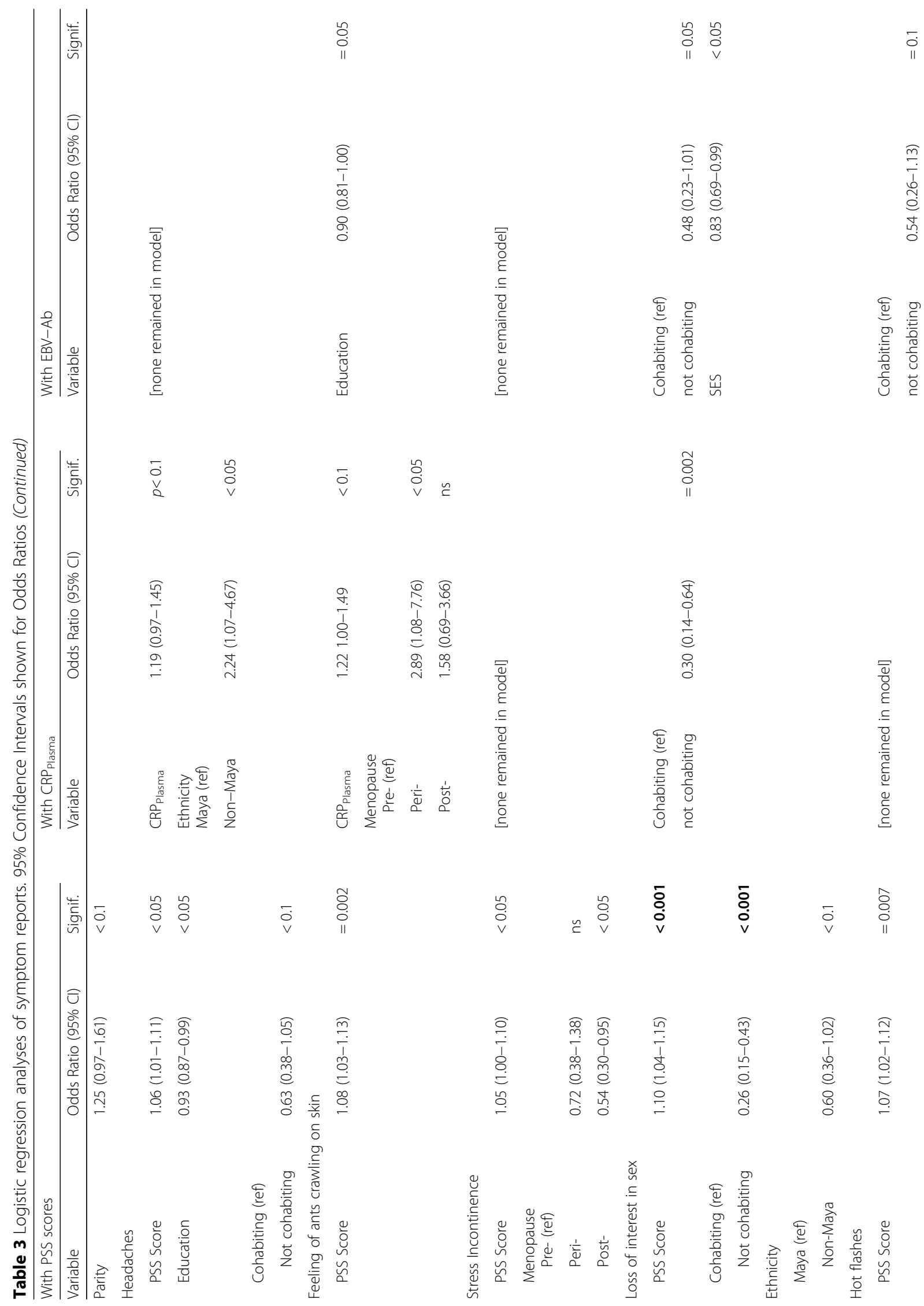


Sievert et al. Women's Midlife Health (2018) 4:9

Page 9 of 15

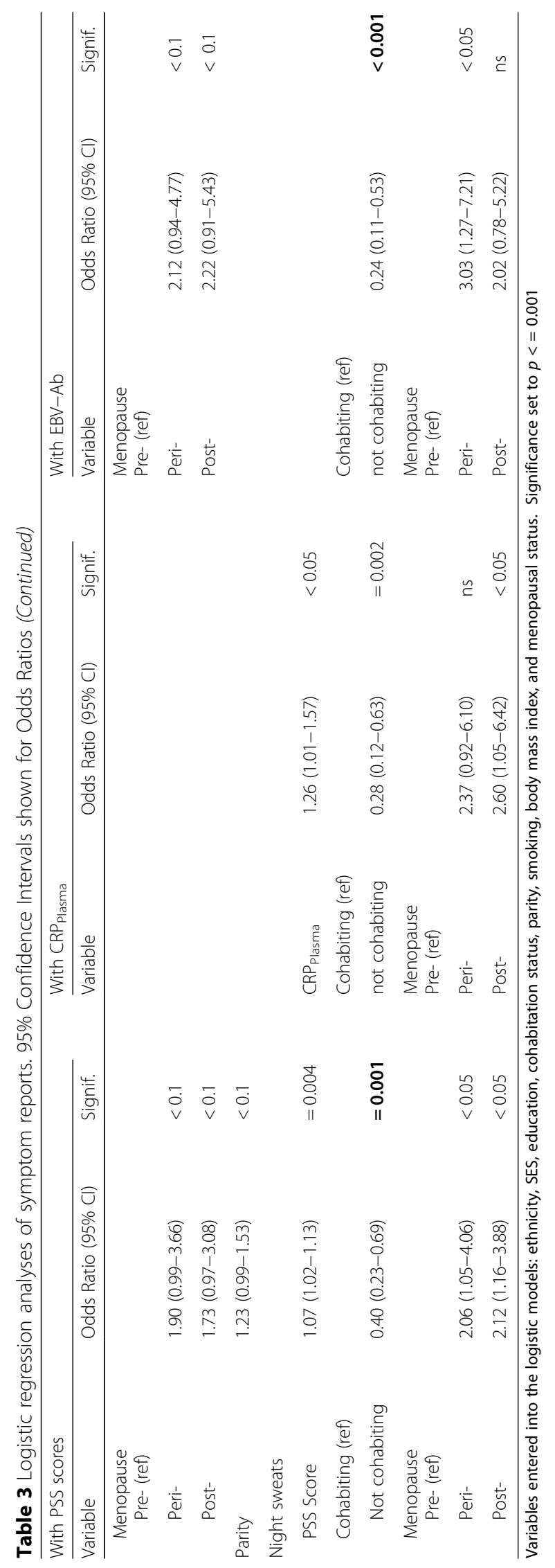


and 0.002 , respectively - slightly above the conservative Bonferroni correction of $p \leq 0.001$. EBV-Ab and $\mathrm{CRP}_{\text {Plasma }}$ levels were not significantly associated with any of the symptoms.

Along with the PSS score, not cohabiting with a husband or partner significantly decreased report of the loss of interest in sex and the likelihood of night sweats. Along with the PSS score, number of children was positively associated with the risk of tiredness and nervousness, although not at the level of $p \leq 0.001$. Overall, the PSS score was the variable most likely to be associated with symptom frequencies.

When the logistic regressions were carried out separately by ethnicity, for Maya, the PSS score was significantly associated with tiredness, feeling nervous/tense, difficulty concentrating, depressed mood, and night sweats $(p \leq 0.001)$; for non-Maya, the PSS score was significantly associated with reported tiredness, depressed mood, and sleep difficulties (not shown). CRP Plasma levels and EBV-Ab values were not significantly associated with any symptom reports for Maya or non-Maya when ethnic groups were examined separately.

As shown in Table 4, the PSS score was significantly associated with the intensity (nada $=0$ to muchisimo $=3$ ) of ten of the 12 reported symptoms, including hot flashes and night sweats $(p \leq 0.001)$. CRP Plasma levels and EBV-Ab values were not significantly associated with the intensity of any symptom reports. When regressions were carried out separately by ethnicity, among Maya participants, the PSS score was significantly associated with the intensity of feeling tired, muscle/joint pain, feeling nervous/tense, difficulty concentrating, depressed mood, difficulty sleeping, and night sweats ( $\mathrm{p} \leq 0.001$ ); for non-Maya, the PSS score was significantly associated with the intensity of the same symptoms except for night sweats. Among the Maya, the association between the PSS score and hot flashes approached significance $(p=0.002)$. $\mathrm{CRP}_{\text {Plasma }}$ levels were not associated with symptoms among the Maya or non-Maya. EBV-Ab values were not significantly associated with any reported symptom intensity among the Maya or non-Maya.

Along with the PSS score, level of education was negatively associated with the intensity of muscle and joint pain. Cohabiting with a husband or partner was positively associated with the intensity of the loss of interest in sex. Progression through menopause was associated with the increased intensity of night sweats.

\section{Discussion}

In this urban population of women aged 40 to 60 from Campeche, Mexico, hot flashes and night sweats were not the most commonly reported symptoms. This finding is consistent with other studies that have found aches and stiffness [32, 60, 65], lack of energy [59], and tiredness or fatigue $[61,66]$ to be more common than hot flashes.

Correlations between self-report measures and biological markers of stress tend to be small or moderate [38]. In the case of this Campeche sample, there were no significant relationships between self-reports of stress (PSS score) and the potentially stress-sensitive biological measures (EBV-Ab and CRP levels), although the two measures of immune function were positively and significantly correlated. None of the measures used in this study were solely measuring stress; there are many factors that can influence immune system activity, and the PSS measures perceptions of stress which can be quite variable in different individuals [38]. It may be that biological measures were elevated in relation to immunological stress, but that immunological activity did not correlate with the impact of stress on the participants within the context of their lives. It may be that these particular biomarkers were not sensitive enough, or that the biomarkers could not effectively measure stress as perceived by the person.

Self-reported PSS was found to be significantly associated with nine of the most common symptoms in bivariate analyses, and with seven symptoms after controlling for potential covariates, whereas neither CRP nor EBV-Ab were associated with symptoms. PSS scores were also associated with the intensity of ten reported symptoms, including hot flashes and night sweats. No other variable in the logistic or linear models was associated with so many midlife symptoms. Our findings are similar to the relationship reported by SWAN researchers who found that the PSS score was significantly associated with vasomotor symptoms [15].

When logistic regressions were carried out separately by ethnicity, the PSS score was significantly associated with five of the reported symptoms among Maya women, including night sweats $(n=144)$. However, among non-Maya women $(n=121)$ the PSS score was significantly associated with only three of the symptoms. These ethnic differences may reflect cultural differences in either the experience or reporting of vasomotor and other symptoms [38, 67]. For Maya women, symptoms may be a means of expressing feelings of stress [11], more so than for non-Maya women.

In results reported here, Maya and non-Maya women did not differ in mean PSS scores; however, Maya women with higher PSS scores were more likely to report a higher intensity of hot flashes $(p=0.002)$ and the presence of and a higher intensity of night sweats $(p \leq 0.001)$. It is of interest to note that earlier literature found an absence of hot flash report among Maya women in the Yucatán peninsula $[42,43,68]$. In contrast, the study presented here did not find an ethnic 
Sievert et al. Women's Midlife Health (2018) 4:9

Page 11 of 15

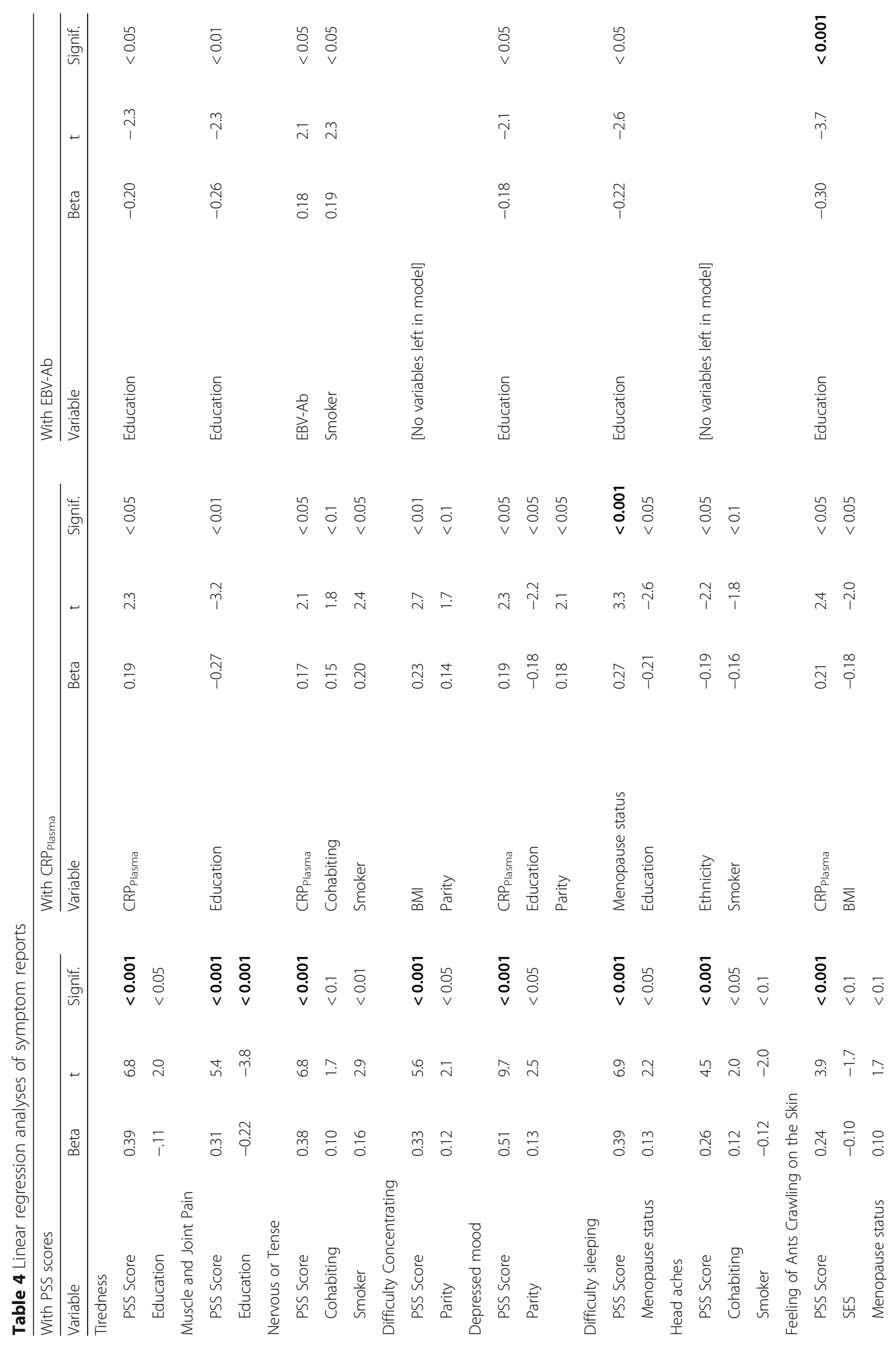


Sievert et al. Women's Midlife Health (2018) 4:9

Page 12 of 15

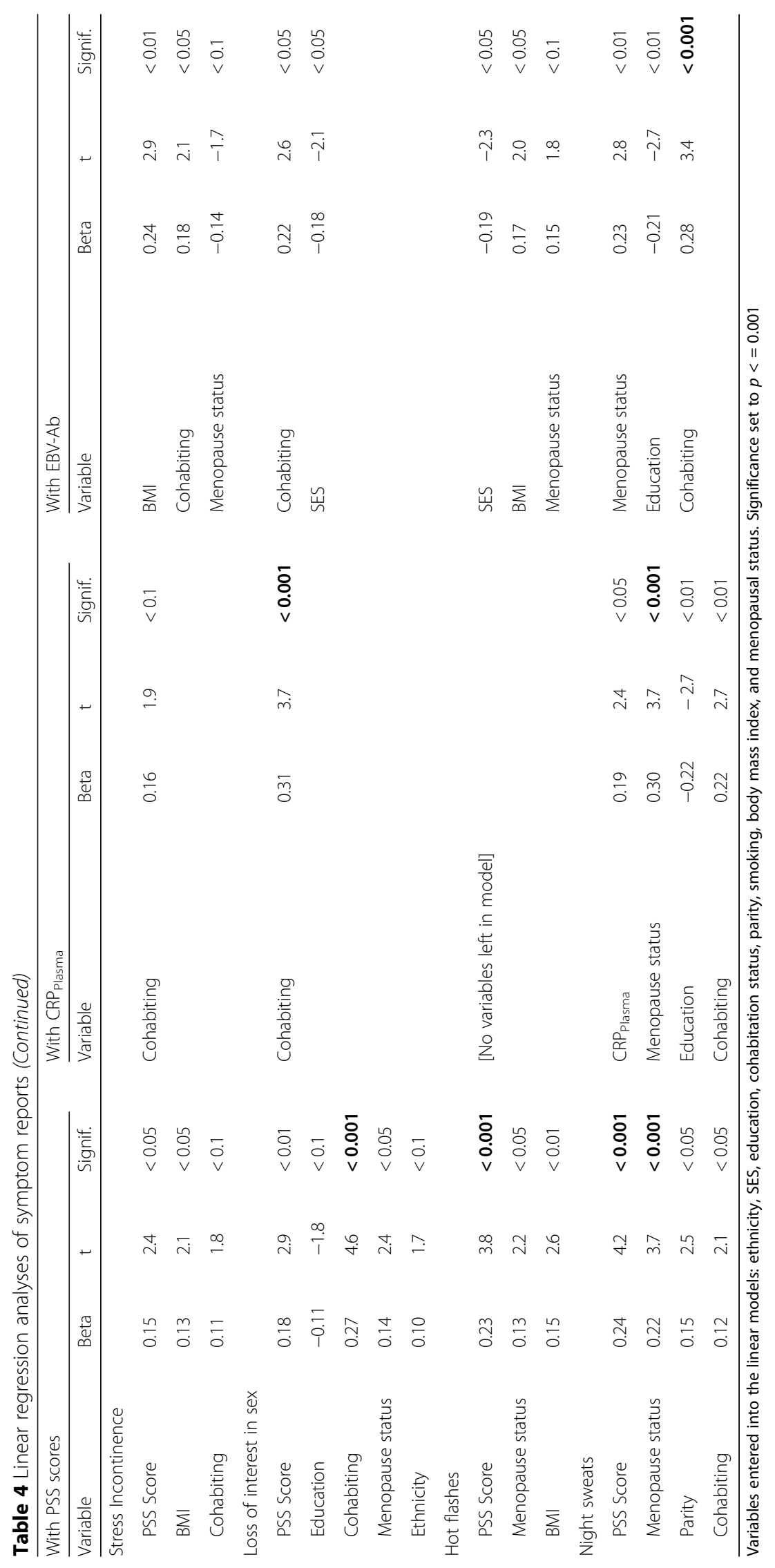


difference in hot flash report, but instead found a greater likelihood of vasomotor symptoms among the Maya in relation to higher perceived levels of stress. This bears further investigation.

This study provides only modest support for the idea that immune biomarkers applied as stress-sensitive measures are associated with the frequency of symptoms at midlife. The relationship between $\mathrm{CRP}_{\text {Plasma }}$ levels and the occurrence of depressed mood did not reach significance, although there was a suggestion of a relationship in bivariate and linear regression analyses $(p<0.05)$. The association between CRP levels and depressed mood has been previously noted [69].

In agreement with our findings, one other previous study did not find a relationship between CRP and hot flashes [70]. In SWAN, women who had a higher frequency of hot flashes had significantly higher levels of CRP and other biological markers of inflammation, but there was no significant association between night sweat frequency and inflammatory markers [71].

EBV-Ab values were not significantly associated with hot flashes or night sweats in terms of yes/no frequency or intensity of report. To our knowledge, this is the first study to examine symptoms at midlife in relation to

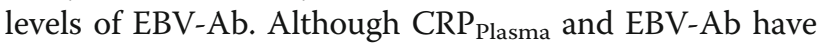
been used as stress-sensitive biological measures in the study of stress in the past $[47,50,51]$, in this study nei-

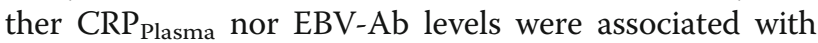
symptoms at midlife to the same extent as the self-reported stress measure, PSS.

Self-reports of stress have been associated with the frequency of hot flashes, both with short-term reports such as hassles scales [72] and reports of chronic stress [73]. However, there may well be differences in the association between stress and hot flashes depending upon the manner in which hot flashes are measured. For example, in a prospective study of mood and hot flashes, negative mood was associated with fewer objectively measured hot flashes but was associated with more frequent self-reported hot flashes [19]. In this study, PSS scores were significantly associated with the intensity of vasomotor symptoms when correction for multiple testing was applied, and PSS scores tended to be associated with the likelihood of vasomotor symptoms $(p=0.007$ and $p=0.004$ for hot flashes and night sweats), unlike the physiological measures of stress.

In general, women who reported high levels of perceived stress were also more likely to report a broad array of symptoms. Some of these symptoms are specific to menopause, such as night sweats, but many are more general concerns of men and women of a broad age range. These symptoms are associated with multiple factors. For example, not cohabiting with a husband or partner significantly decreased report of the loss of interest in sex.

Self-reported stress is clearly implicated as associated with symptoms, especially among the Maya in this sample. It is, however, unclear to what degree stress may be a causal factor in inducing these symptoms, or if instead the symptoms are a causal factor in the stress levels. There could be a reciprocal effect, with stress inducing symptoms that in turn lead to greater perceptions of stress. Few women reported either no symptoms (1.4\%) or all 12 symptoms (5.4\%), suggesting that there is not a simple relation between being under stress and having all symptoms; different women suffer from different symptoms, and these are likely to differ in the importance of stress levels for their occurrence. It is unclear why the stronger association between perceived stress and vasomotor symptoms is present among Maya but not non-Maya participants. The women may differ in beliefs about how stress should be reported, since ethnic differences in self-reports of stress are found in other populations [38].

This study has limitations. While the sample is likely to broadly represent the population of women at midlife in Campeche due to the multiple strategies used for contacting potential participants, it is not a random sample. The sample size is small, with 305 women providing PSS scores, and only 162 and 157 women with EBV-Ab and CRP measures, respectively. We did not find the expected relationship between the PSS and the two biomarkers. Also, this paper has relied upon self-reports of hot flashes and night sweats as well as other symptoms. As noted, a previous study has shown a difference in the relation between stress and either subjectively reported or objectively measured hot flashes [19]. Finally, this study is cross-sectional and, therefore, cannot derive causation from associations between the variables used in analyses.

\section{Conclusions}

In support of our primary hypothesis, perceived stress was associated with the intensity of hot flashes and night sweats. In logistic and linear regressions, perceived stress was the variable most consistently associated with each of the 12 symptoms studied. This was not true for the potentially stress-sensitive biological measures of EBV-

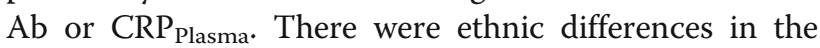
associations between measures of stress and symptom frequency and intensity. Maya women demonstrated a relationship between perceived stress and five symptoms, including night sweats, while the non-Maya demonstrated no association between between perceived stress and vasomotor symptoms, suggesting that either symptoms or stress were experienced and/or reported in culture-specific ways. 


\section{Acknowledgements}

We are indebted to the women who participated and authorities of the city of Campeche. Special thanks to Drs. Alfonso Cobos Toledo, Secretario de Salud; Carlos Juárez López, Secretario Técnico del Comité de Ética en Investigación; and Liliana Montejo León, Directora Operativa del Comité de Ética de Investigación. For assistance with fieldwork, we thank Isai Delgado, Gía del Pino, Guadalupe Islas Monter, Lizbeth de las Mercedes Rodríguez, Giselle O'Connor, Elena Pasqual, and Alba Valdéz Tah. In addition, we thank Drs. Jorge Jiménez Madrigal, Diana Edith Arceo Sánchez, Miguel Briceño Dzib, Enrique Fernando Reyes Pascual; Lic. Francisco Góngora Ramírez, and especially Lic. Marlene Narváez Rosado. Authorities who facilitated the interviews by giving us the needed space include Dra. Landy del Socorro Ortíz Aldana, Ing. Jorge Marín Farías Maldonado, M. en C. Lirio Suárez Améndola, Antrop. Marco Carvajal, Dra. Lizbeth Rodríguez, Lic. Lidia Elena Berrón Osorio, Lic. Ana Verónica Lemus Castillo, Lic. José Dolores Uribe Castro, Ing. Leidy Elena Legorreta Barrancos, Ing. Rosario Suárez Améndola, Ing. José Luis Herrera Martínez, Lic. Cecilia Zúñiga Rosel, Lic. Lorenzo Alberto Can Sánchez, Lic. Yolanda Isabel Segovia Cuevas, Ing. José Raúl Ochoa Aguedo, Ing. Agustín Balvanera Aguilar, Lic. Román Acosta Estrella, Lic. Ricardo Ocampo Fernández, Lic. Margarita Alfaro Waring. Finally, we thank Prof. Martha del Carmen Preciat Castilla and Lic. Rosa Angélica Prevé Quintero for their enthusiastic support of this study.

\section{Funding}

Supported by NSF BCS-1156368.

\section{Availability of data and materials}

At present, the datasets used and analyzed during the current study are available from the corresponding author on reasonable request. All data will eventually be available through Scholarworks at UMass Amherst.

\section{Authors' contributions}

LLS, LHG, and DB designed this study; data collection was carried out and supervised by LHG and DCC in collaboration with LLS and DB; DLK carried out laboratory assays; DB and LLS carried out all analyses; LLS and DB drafted the manuscript; all authors read and approved the final manuscript.

\section{Ethics approval and consent to participate}

This study was approved by the Institutional Review Board of the University of Massachusetts Amherst; the Human Subjects Committee of the University of Hawaii at Hilo; and the Committee for Ethics in Research of the Secretary of Health in the State of Campeche, Mexico. All participants signed a letter of consent after lengthy explanation in Spanish.

\section{Consent for publication}

Not applicable

\section{Competing interests}

The authors declare that they have no competing interests.

\section{Publisher's Note}

Springer Nature remains neutral with regard to jurisdictional claims in published maps and institutional affiliations.

\section{Author details}

'Department of Anthropology, Machmer Hall, 240 Hicks Way, UMass Amherst, Amherst, MA 01003-9278, USA. ²Departamento de Sociedad y Cultura, El Colegio de la Frontera, ECOSUR, Campeche, México. ${ }^{3}$ Department of Pharmaceutical Science, University of Hawai'i at Hilo, Hilo, HI, USA. ${ }^{4}$ Department of Anthropology, University of Hawai'i at Hilo, Hilo, HI, USA.

\section{Received: 21 December 2017 Accepted: 29 May 2018} Published online: 18 June 2018

\section{References}

1. Freedman RR. Menopausal hot flashes: mechanisms, endocrinology, treatment. J Steroid Biochem Mol Biol. 2014;142:115-20.

2. World Health Organization. Research on the menopause in the 1990s, WHO technical report series, 866. Geneva: World Health Organization; 1996.
3. Kravitz HM, Ganz PA, Bromberger J, Powell LH, Sutton-Tyrrell K, Meyer PM. Sleep difficulty in women at midlife: a community survey of sleep and the menopausal transition. Menopause. 2003;10:19-28.

4. de Kruif M, Spijker AT, Molendijk ML. Depression during the perimenopause: a meta-analysis. J Affect Disord. 2016;206:174-80.

5. Ryan J, Burger H, Szoeke C, Lehert P, Ancelin M-L, Dennerstein L. A prospective study of the association between endogenous hormones and depressive symptoms in postmenopausal women. Menopause. 2009;16(3):509-17.

6. Ford K, Sowers M, Crutchfield M, Wilson A, Jannausch M. A longitudinal study of the predictors of prevalence and severity of symptoms commonly associated with menopause. Menopause. 2005;12(3):308-17.

7. Dennerstein L. Well-being, symptoms and the menopausal transition. Maturitas. 1996;23:147-57.

8. Darling CA, Coccia C, Senatore N. Women in midlife: stress, health and life satisfaction. Stress Health. 2012:28:31-40.

9. Staner L. Sleep and anxiety disorders. Dialogues Clin Neurosci. 2003;5(3):249-58.

10. Hammen C. Stress and depression. Annu Rev Clin Psychol. 2005;1:293-319.

11. Sievert LL, Obermeyer CM. Symptom clusters at midlife: a four-country comparison of checklist and qualitative responses. Menopause. 2012;19(2):133-44.

12. Sievert $L L$, Obermeyer CM, Saliba M. Symptom groupings at midlife: crosscultural variation and association with job, home, and life change. Menopause. 2007:14(4):798-807.

13. Avis NE, Crawford SL, Greendale G, Bromberger JT, Everson-Rose SA, Gold EB, Hess R, Joffe H, Kravitz HM, Tepper PG, Thurston RC, Study of Women's Health Across the Nation. Duration of menopausal vasomotor symptoms over the menopause transition. JAMA Intern Med. 2015;175(4):531-9.

14. Freeman EW, Sammel MD, Lin H, Liu Z, Gracia CR. Duration of menopausal hot flushes and associated risk factors. Obstet Gynecol. 2011;117(5):1095-104.

15. Gold EB, Block G, Crawford S, Lachance L, FitzGerald G, Miracle H, Sherman S. Lifestyle and demographic factors in relation to vasomotor symptoms: baseline results from the study of Women's Health Across the Nation. Am J Epidemiol. 2004;159(12):1189-99.

16. Kuh DL, Wadsworth M, Hardy R. Women's health in midlife: the influence of the menopause, social factors and health in earlier life. Br J Obstet Gynaecol. 1997;104(8):923-33.

17. Thurston RC, Bromberger J, Chang Y, Goldbacher E, Brown C, Cyranowski JM, Matthews KA. Childhood abuse or neglect is associated with increased vasomotor symptom reporting among midlife women. Menopause. 2008;15:16-22.

18. Binfa L, Castelo-Branco C, Blümel JE, Cancelo MJ, Bonilla H, Muñoz I, Vergara V, Izaguirre H, Sarrá S, Ríos RV. Influence of psycho-social factors on climacteric symptoms. Maturitas. 2004;48(4):425-31.

19. Thurston RC, Blumenthal JA, Babyak MA, Sherwood A. Emotional antecedents of hot flashes during daily life. Psychosom Med. 2005;67(1):137-46.

20. Swartzman LC, Edelberg R, Kemmann E. Impact of stress on objectively recorded menopausal hot flushes and on flush report bias. Health Psychol. 1990;9:529-45.

21. Pollard TM, Ice GH. Measuring hormonal variation in the hypothalamic pituitary adrenal (HPA) axis: cortisol. In: Ice GH, James GD, editors. Measuring stress in humans: a practical guide for the field. Cambridge: Cambridge University Press; 2007. p. 122-57.

22. Cignarelli M, Cicinelli E, Corso M, et al. Biophysical and endocrinemetabolic changes during menopausal hot flashes: increase in plasma free fatty acid and norepinephrine levels. Gynecol Obstet Investig. 1989;27:34-7.

23. Meldrum DR, Defazio JD, Erlik Y, et al. Pituitary hormones during the menopausal hot flash. Obstet Gynecol. 1984;64:752-6.

24. Woods NF, Carr MC, Tao EY, Taylor HJ, Mitchell ES. Increased urinary cortisol levels during the menopausal transition. Menopause. 2006;13(2):212-21.

25. Cagnacci A, Cannoletta M, Caretto S, Zanin R, Xholli A, Volpe A. Increased cortisol level: a possible link between climacteric symptoms and cardiovascular risk factors. Menopause. 2011;18(3):273-8.

26. Reed SD, Newton KM, Larson JC, Booth-LaForce C, Woods NF, Landis CA, Tolentino E, Carpenter JS, Freeman EW, Joffe H, Anawalt BD, Guthrie KA. Daily salivary cortisol patterns in midlife women with hot flashes. Clin Endocrinol. 2016;84(5):672-9.

27. Rubin LH, Drogos LL, Kapella MC, Geller SE, Maki P. Cortisol awakening response differs for midlife women with objective vasomotor symptoms versus without vasomotor symptoms. Menopause. 2014;21(12):1362. [abstract]

28. Gerber LM, Sievert LL, Schwartz JE. Hot flashes and midlife symptoms in relation to levels of salivary cortisol. Maturitas. 2017;96:26-32. 
29. Greenberg GP, Sievert LL. Is there a relationship between hot flashes, night sweats, and the cortisol awakening response? Am J Hum Biol. 2018;30(2): e23110. [abstract]

30. Gibson CJ, Thurston RC, Matthews KA. Cortisol dysregulation is associated with daily diary-reported hot flashes among midlife women. Clin Endocrinol. 2016;85(4):645-51.

31. Avis NE, Stellato R, Crawford S, et al. Is there a menopausal syndrome? Menopausal status and symptoms across racial/ethnic groups. Soc Sci Med. 2001;52:345-56

32. Lerner-Geva L, Boyko V, Blumstein T, Benyamini Y. The impact of education, cultural background, and lifestyle on symptoms of the menopausal transition: the Women's Health at Midlife Study. J Women's Health (Larchmt). 2010;19:975-85.

33. Sievert LL, Morrison L, Brown DE, Reza AM. Vasomotor symptoms among Japanese-American and European-American women living in Hilo, Hawaii. Menopause. 2007;14:261-9

34. Brown DE. Physiological stress and culture change in a group of FilipinoAmericans: a preliminary investigation. Ann Hum Biol. 1982;9(6):553-63.

35. Brown DE, James GD, Nordloh L. Comparison of factors affecting daily variation of blood pressure in Filipino-American and Caucasian nurses in Hawaii. Am J Phys Anthropol. 1998;106(3):373-83.

36. Brown DE, Sievert LL, Morrison LA, Rahberg N, The RAM. Relation between hot flashes and ambulatory blood pressure: the Hilo Women's health study. Psychosom Med. 2011;73:166-72.

37. Dressler WW, Oths KS, Gravlee CC. Race and ethnicity in public health research: models to explain health disparities. Annu Rev Anthropol. 2005;34:231-52.

38. Brown DE. Stress biomarkers as an objective window on experience. In: Sievert $\mathrm{LL}$, Brown DE, editors. Biological measures of human experience across the lifespan: making visible the invisible. New York: Springer; 2016. p. 117-41.

39. Beyene $Y$, Martin MC. Menopausal experiences and bone density of Mayan women in Yucatan, Mexico. Am J Hum Biol. 2001;13:505-11.

40. Canto-de-Cetina TE, Canto-Cetina P, Polanco-Reyes L. Encuesta de sintomas del climaterio en areas semirurales de Yucatan. Revista de Investigacion Clinica. 1998:50:133-5.

41. Gold EB, Crawford SL, Avis NE, Crandall CJ, Matthews KA, Waetjen LE, Lee JS, Thurston R, Vuga M, Harlow SD. Factors related to age at natural menopause: longitudinal analyses from SWAN. Am J Epidemiol. 2013;178:70-83.

42. Beyene Y. Cultural significance and physiological manifestations of menopause: a biocultural analysis. Cult Med Psych. 1986;10:47-71.

43. Beyene Y. From menarche to menopause: reproductive histories of peasant women in two cultures. Albany: State University of New York Press; 1989.

44. Malacara JM, Canto-de-Cetina T, Bassol S, Gonzalez N, Cacique L, VeraRamirez ML, Nava LE. Symptoms at pre- and postmenopause in rural and urban women from three states of Mexico. Maturitas. 2002:43:11-9.

45. Eick G, Urlacher SS, McDade TW, Kowal P, Snodgrass JJ. Validation of an optimized ELISA for quantitative assessment of Epstien-Barr virus antibodies from dried blood spots. Biodemography Soc Biol. 2016;62(2):222-33.

46. McDade TW, Stallings JF, Angold A, Costello EJ, Burleson M, Cacioppo JT, Glaser R, Worthman CM. Epstein-Barr virus antibodies in whole blood spots: a minimally invasive method for assessing an aspect of cell-mediated immunity. Psychosom Med. 2000;62(4):560-7.

47. McDade TW. Measuring immune function: markers of cell-mediated immunity an inflammation in dried blood spots. In: Ice GH, James GD, editors. Measuring stress in humans: a practical guide for the field. Cambridge: Cambridge University Press; 2007. p. 181-207.

48. Wium-Andersen MK, Orsted DD, Nielsen SF, Nordestgaard BG. Elevated C-reactive protein levels, psychological distress, and depression in 73,131 individuals. JAMA Psychiatry. 2013;70(2):176-84.

49. Black PH, Garbutt LD. Stress, inflammation and cardiovascular disease. J Psychosom Res. 2002;52:1-23.

50. Low CA, Matthews KA, Hall M. Elevated CRP in adolescents: roles of stress and coping. Psychosom Med. 2013;75(5):449-52.

51. Steptoe A, Hamer M, Chida Y. The effects of acute psychological stress on circulating inflammatory factors in humans: a review and meta-analysis. Brain Behav Immun. 2007;21:901-12.

52. McDade TW. Status incongruity in Samoan youth: a biocultural analysis of culture change, stress, and immune function. Med Anthropol Q. 2002;16(2):123-50.
53. INEGI. Anuario estadístico y geográfico de Campeche, 2014. Instituto Nactional de Estadística y Geografía. Aguascalientes: INEGl; 2014. www.inegi.org.mx

54. Huicochea Gómez L, Sievert LL, Cahuich Campos D, Brown DE. An investigation of life circumstances associated with the experience of hot flashes in Campeche, Mexico. Menopause. 2017;24(1):52-63.

55. Harlow SD, Gass M, Hall JE, Lobo R, Maki P, Rebar RW, Sherman S, Sluss PM, de Villiers TJ, STRAW+ 10 Collaborative Group. Executive summary of the Stages of Reproductive Aging Workshop+ 10: addressing the unfinished agenda of staging reproductive aging. Menopause. 2012;19(4):387-95.

56. González Ramírez MT, Landero Hernández R. Factor structure of the perceived stress scale (PSS) in a sample from Mexico. Spanish J Psychol. 2007;10:199-206.

57. Cohen S, Kamarck T, Mermelstein R. A global measure of perceived stress. J Health Soc Behav. 1983;24:386-96.

58. Cohen S, Williamson G. Perceived stress in a probability sample of the United States. In: Spacapan S, Oskamp S, editors. Social psychology of health. Newbury Park: Sage; 1988. p. 31-67.

59. Avis NE, Kaufert PA, Lock M, McKinlay SM, Vass K. The evolution of menopausal symptoms. Bailliere's Clin Endocrinol Metab. 1993;7:17-32.

60. Dennerstein L, Smith AMA, Morse C, Burger H, Green A, Hopper J, Ryan M. Menopausal symptoms in Australian women. Med J Aust. 1993;159:232-6.

61. Obermeyer CM, Reher D, Saliba M. Symptoms, menopause status, and country differences: a comparative analysis from DAMES. Menopause. 2007:14:788-97.

62. Sievert LL, Espinosa-Hernandez G. Attitudes toward menopause in relation to symptom experience in Puebla, Mexico. Women Health. 2003;38(2):93-106.

63. McDade TW, Burhop J, Dohnal J. High-sensitivity enzyme immunoassay for C-reactive protein in dried blood spots. Clin Chem. 2004;50(3):652-4.

64. Pearson TA, Mensah GA, Alexander RW, Anderson JL, Cannon RO 3rd, Criqui M, Fadl YY, Fortmann SP, Hong Y, Myers GL, Rifai N, Smith SC Jr, Taubert K, Tracy RP, Vinicor F. Markers of inflammation and cardiovascular disease: application to clinical and public health practice: a statement for healthcare professionals from the Centers for Disease Control and Prevention and the American Heart Association. Circulation. 2003;107(3):499-511.

65. Melby MK. Factor analysis of climacteric symptoms in Japan. Maturitas. 2005;52:205-22.

66. Hemminki $E$, Topo $P$, Kangas I. Experience and opinions of climacterium by Finnish women. Eur J Obstet Gynecol. 1995;62:81-7.

67. Brown DE. General stress in anthropological fieldwork. Am Anthropol. 1981;83(1):74-92.

68. Martin MC, Block JE, Sanchez SD, Arnaud CD, Beyene Y. Menopause without symptoms: the endocrinology of menopause among rural Mayan Indians. Am J Obstet Gynecol. 1993;168:1839-45.

69. Valkanova V, Ebmeier KP, Allan CL. CRP, IL-6 and depression: a systematic review and meta-analysis of longitudinal studies. J Affect Disord. 2013;150(3):736-44.

70. Bechlioulis A, Naka KK, Kalantaridou SN, Kaponis A, Papanikolaou O, Vezyraki P, Kolettis TM, Vlahos AP, Gartzonika K, Mavridis A, Michalis LK. Increased vascular inflammation in early menopausal women is associated with hot flush severity. J Clin Endocrinol Metab. 2012;97(5):E760-4.

71. Thurston RC, El Khoudary SR, Sutton-Tyrrell K, Crandall CJ, Gold E, Sternfeld B, Selzer F, Matthews KA. Are vasomotor symptoms associated with alterations in hemostatic and inflammatory markers? Findings from the study of Women's Health Across the Nation. Menopause. 2011;18(10):1044-51.

72. Gannon L, Hansel S, Goodwin J. Correlates of menopausal hot flashes. J Behav Med. 1987;10(3):277-85.

73. Gannon L, Luchetta T, Pardie L. Perimenstrual symptoms: relationships with chronic stress and selected lifestyle variables. J Behav Med. 1989;15(4):149-59. 